University of Nebraska - Lincoln

DigitalCommons@University of Nebraska - Lincoln

Roman L. Hruska U.S. Meat Animal Research

U.S. Department of Agriculture: Agricultural Center

Research Service, Lincoln, Nebraska

2004

\title{
Soil quality: a review of the science and experiences in the USA
}

B. J. Wienhold

University of Nebraska-Lincoln, Brian.Wienhold@ars.usda.gov

S. S. Andrews

USDA-NRCS

D. L. Karlen

USDA-ARS

Follow this and additional works at: https://digitalcommons.unl.edu/hruskareports

Wienhold, B. J.; Andrews, S. S.; and Karlen, D. L., "Soil quality: a review of the science and experiences in the USA" (2004). Roman L. Hruska U.S. Meat Animal Research Center. 211.

https://digitalcommons.unl.edu/hruskareports/211

This Article is brought to you for free and open access by the U.S. Department of Agriculture: Agricultural Research Service, Lincoln, Nebraska at DigitalCommons@University of Nebraska - Lincoln. It has been accepted for inclusion in Roman L. Hruska U.S. Meat Animal Research Center by an authorized administrator of DigitalCommons@University of Nebraska - Lincoln. 


\title{
Soil quality: a review of the science and experiences in the USA
}

\author{
B.J. Wienhold ${ }^{1,4}$, S.S. Andrews ${ }^{2}$ \& D.L. Karlen ${ }^{3}$ \\ ${ }^{1}$ USDA-ARS, 120 Keim Hall, East Campus, UNL, Lincoln, NE 68583-0934, USA \\ ${ }^{2}$ USDA-NRCS, Ames, IA 50011, USA \\ ${ }^{3}$ USDA-ARS, Ames, IA 50011, USA \\ ${ }^{4}$ Author for correspondence (tel.: +1-402-472-1484; fax: +1-402-472-0516; e-mail: bwienhold1@unl.edu
}

Received 17 February 2003 Accepted 18 August 2003

Key words: grazing, soil assessment, soil function, soil management, soil quality index

\begin{abstract}
An increasing human population is placing greater demand on soil resources, and as a result degradation is taking place in many regions of the world. This is critical because soils perform a number of essential processes including supporting food and fiber production, influencing air quality through interaction with the atmosphere, and serving as a medium for storage and purification of water. The soil quality concept was introduced to complement soil science research by making our understanding of soils more complete and helping guide the use and allocation of labor, energy, fiscal, and other inputs as agriculture intensifies and expands to meet increasing world demands. Soil quality thus provides a unifying concept for educating professionals, producers, and the public about the important processes that soils perform. It also provides an assessment tool for evaluating current management practices and comparing alternative management practices. Soil attributes comprising a minimum data set have been identified, and both laboratory and field methods have been developed for measuring them. A soil quality index is being developed to normalize measured soil quality indicator data and generate a numeric value that can be used to compare various management practices or to assess management-induced changes over time. Using previously published data, we evaluated the soil quality index as a tool to assess a wide range of management practices in the Northern Great Plains. The index ranked the treatments: grazed fertilized tame pasture $>$ moderately grazed $>$ ungrazed $>$ heavily grazed $>$ annual cropping with no-tillage $>$ conventionally tilled cropfallow which agrees with the way they were subjectively ranked in the publications. The soil quality index shows potential for use as a management assessment tool.
\end{abstract}

\section{Introduction}

Soil forms a thin layer over the surface of the earth that performs many processes essential to life. It serves as a substrate supporting plant growth, as a nutrient reservoir, and as the site for many biological processes involved in decomposition and recycling of plant and animal products. Soils influence air quality through interactions with the atmosphere and as a storage and purification medium for water as it passes through the soil profile. The importance of soils to humankind is documented by the many ancient civilizations that have collapsed or relocated because mismanagement destroyed the soils on which they depended.

The human population is increasing with estimates suggesting that there will be an additional 1 billion people on the earth within a decade (Haub \& Farnsworth-Riche 1994). Current levels of crop production will not be sufficient to meet food needs within the near future (30 years) and grain yields will have to increase from $1.2 \%$ (for wheat and rice) to $1.5 \%$ (for corn) per year to meet demand (Rosegrant et al. 1998). Opportunities for expanding production to uncultivated land are 
Table 1. Physical, chemical, and biological soil indicators that may be included in a minimum data set for assessing soil quality.

\begin{tabular}{lll}
\hline Physical & Chemical & Biological \\
\hline Texture & Organic C & Microbial biomass C and N \\
Depth of topsoil & Total N & Potentially mineralizable N \\
Infiltration & $\mathrm{pH}$ & Soil respiration \\
Bulk density & Electrical conductivity & \\
Water holding capacity & Extractable N, P, K & \\
\hline
\end{tabular}

limited as much of the arable land is currently in production. In addition to agricultural production, soils are used for a range of other uses (e.g. recreation, forestry, and urban development). Mismanagement by man, brought on by increasing demands, has resulted in the degradation of soil by erosion, salinization, and waterlogging at a rate of 10 million ha per year (Pimentel et al. 1995). In order to insure that the processes performed by soils are sustained, tools for assessing soil processes and for evaluating the effect management practices have on soil processes are needed. In (1977) Warkentin \& Fletcher introduced soil quality as a concept to complement soil science research by making our understanding of soils more complete and to help guide use and allocation of labor, fiscal and other inputs as agriculture intensifies and expands to meet increasing world demands.

\section{Scientific basis}

In the late 1980's, attention began to shift from erosion and production agriculture to sustainable agriculture, environmental health, and preservation of the soil resource. Larson \& Pierce (1991), proposed a quantitative formula for assessing soil quality and relating the changes to soil management practices. Over the next several years the soil quality concept was further developed through symposia and workshops that resulted in a number of books and proceedings being published (National Research Council 1993; Doran et al. 1994; Doran \& Jones 1996). The Soil Science Society of America appointed a committee to define the concept of soil quality, examine its rationale and justification, and identify the soil and plant attributes useful for description and evaluation of the concept. This committee defined soil quality as "the capacity of a specific kind of soil to function, within natural or managed boundaries, to sustain plant and animal productivity, maintain or enhance water and air quality, and support human health and habitation' (Karlen et al. 1997).

Soil processes are evaluated by measuring a suite of physical, chemical, and biological soil attributes that comprise a definable minimum data set (Table 1). Nearly all of the physical, chemical, and biological attributes that comprise a minimum data set have established meanings and published procedures that predate the soil quality concept. It is the use of these attributes to evaluate essential soil processes that makes soil quality a useful tool for assessing system sustainability. Collection of a data set from two or more systems allows for a comparative assessment (Larson \& Pierce 1994). A comparative assessment is useful for determining differences in soil attributes and functions among management practices that have been in place for some period of time. Collection of a data set from a system over time allows for a dynamic assessment. A dynamic assessment is necessary for determining the direction and magnitude of change a management practice is having (Figure 1).

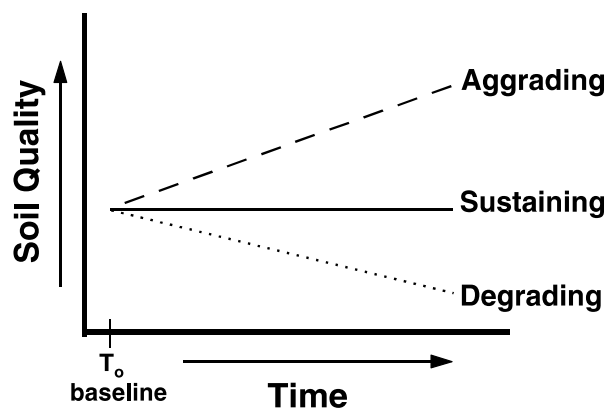

Fig. 1. Conceptual changes in temporal soil quality indicating degradation, maintenance, or improvement (adapted from Seybold et al. 1998). 


\section{Soil quality as a tool for assessing sustainability}

Soil quality is proving itself useful as an educational concept and as an assessment tool. Soil quality has been used to make students, policymakers, producers, and the public more aware of the essential processes soils perform. As an assessment tool, soil quality allows for a hands-on observation of soil processes and provides producers and managers with additional information to be used in making management decisions.

In the United States, soil quality education is carried out by a variety of government, university, and professional organizations. In 1994, the Soil Quality Institute of the United States Department of Agriculture Natural Resources Conservation Service was created to "cooperate with partners in the development, acquisition and dissemination of soil quality information and technology to help people conserve and sustain our natural resources and the environment.' The Soil Quality Institute maintains an Internet site (http://www.statlab. iastate.edu/survey/SQI) publishes information sheets dealing with various aspects of soil quality to promote the soil quality concept. The information sheets cover introductory topics such as 'What is soil quality?', describe soil quality indicators, and present resource concerns related to soil quality (e.g. soil erosion, compaction). Numerous universities include soil quality in their extension activities and publish soil quality guides to help improve understanding of soils and soil quality. The Soil and Water Conservation Society published the 'Soil Biology Primer' to improve understanding of the soil as an environment for a wide variety of life forms. In addition to these examples there have been numerous workshops and field trips held to improve understanding of soil quality.

Soil quality assessment is done to provide guidelines with regard to soil management practices that can lead to improved soil function. This is most effective if the assessment is actually made by those managing the land. To that end a great deal of effort has been expended in the development of soil quality assessment tools that are nontechnical and relatively inexpensive. Farmer interviews were used to develop a soil health scorecard in Wisconsin (Romig et al. 1996). The scorecard lists a series of descriptive properties (e.g. erosion, tillage ease, compaction, infiltration) and provides criteria (e.g. severe erosion, moderate erosion, or little erosion from wind and water) for evaluating that property in a soil health context. The scores can then be used to identify properties that are impaired or unhealthy and in need of management. While the scorecard approach is rather subjective and scores are influenced by interviewee bias, they serve as a valuable tool in making managers more aware of management impacts on soil processes. A more quantitative approach was made possible through the development of the soil quality test kit (Liebig et al. 1996). The test kit is commercially available (Gemplers Inc., Belleville, WI) and provides the equipment and instructions for measuring a number of physical, chemical, and biological soil properties. Results obtained with the test kit compare well with those found using standard laboratory methods (Liebig et al. 1996).

An essential step in using soil quality to assess management practices is the availability of tools which producers or managers can use to interpret the technical soil measures and provide guidance for their management. These tools can take the form of an interpretive guide or a computer program that calculates an index using measured soil property values. These tools can be used to identify problem areas and evaluate management practices over time. The 'USDA Soil Quality Test Kit Manual and Interpretive Guide' (USDANRCS 1998) is a tool designed to accompany the soil quality test kit or be used to interpret data generated with the test kit. This guide has been printed in both English and Spanish and is being widely distributed. A number of studies have evaluated soil quality indicators at point to regional scales (Karlen et al. 1999; Liebig \& Doran 1999; Brejda et al. 2000a, b, c). Gomez et al. (1996) developed an on-farm index for assessing sustainability based on productivity, profitability, stability, and social acceptability. This assessment uses soil processes (e.g. crop yield and frequency of crop failure) or soil properties (e.g. soil depth, organic C) as indicators and identifies threshold values that are based on local conditions to generate an index of sustainability. This example is only one of several approaches that have been used to develop an index which uses soil quality as an indicator for sustainability (Karlen et al. 1998; Hussain et al. 1999; Jaenicke \& Lengnick 1999; Wander \& Bollero 1999; Andrews et al. 2002a, b; Andrews \& Carroll 2001). 


\section{Development of soil quality index functions}

Soil quality indicators can be classified as either inherent or dynamic. Inherent indicators are determined by the soil forming factors of climate, parent material, time, topography, and biota (Jenny 1941). Inherent soil properties and interpretation of how they affect potential land use are the foundation for soil survey, classification, and land use recommendations. Dynamic indicators describe the condition of the soil due to recent ( $<10$ years) land use or management decisions. Dynamic indicators are used to assess how soil management decisions affects use-dependent soil properties.

To compare soil quality indicators among sites or among treatments it is useful to normalize the indicator values using scoring curves. These are mathematical equations developed to describe the relationship between an indicator value and a specific soil process. Indicator selection for a particular process or function can be done using expert opinion or a statistical procedure such as principle component analysis (Andrews et al. 2002b). Scoring curves are constructed to take into account the effects that inherent soil properties (e.g. effect of clay content on the potential for organic $\mathrm{C}$ accumulation) and climate have on the indicator being evaluated (e.g. higher potential for $\mathrm{C}$ accumulation where it is cool and wet than where it is hot and dry). Scoring curves generally have one-of-three

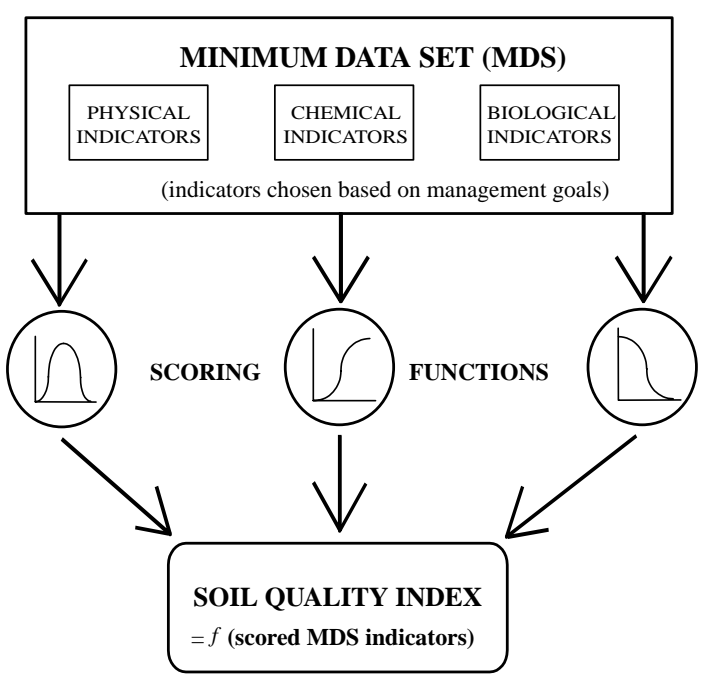

Fig. 2. Conceptual relationship between soil quality minimum data sets, scoring functions, and index values. forms: more is better (a sigmoid shaped curve with an upper asymptote), less is better (a sigmoid shaped curve with a lower asymptote), and an optimum value with higher or lower values being less desirable (a bell shaped curve). Once scoring curves are developed for a soil or group of soils, indicators for a minimum dataset can be quantified for soils under a range of management systems and the indicators can be scored using the curves. The scored values are then combined in some way (additive, multiplied, or weighted) to form an index value for that management system (Figure 2). Index values created in a similar way can then be compared among management systems or over time for a particular management system.

\section{Case studies}

Andrews et al. (2002b) have developed a soil quality index that currently provides functions to normalize macro-aggregate stability, available water content, bulk density, electrical conductivity, microbial biomass carbon, $\mathrm{pH}$, potentially mineralizable nitrogen, respiratory quotient, extractable phosphorus, sodium adsorption ratio, and total organic carbon. This index was tested using data from alternative vegetable production systems near Davis, CA. Expert opinion and principle component analysis were compared as methods for selecting indicators for comparing the various management systems with no difference in outcome between the two approaches. Indicator scores were combined to form an additive index, a weighted index (weighted using the principle component results), or a decision support system index (additive index with the importance order of the components being determined from a growers survey). All of the indexing methods resulted in the organic system receiving a higher soil quality index score than low input or conventional treatments. Results from this initial test suggest that the soil quality assessment index can be used to compare management alternatives using a small number of indicators. The index is currently being compared across a range of sites in the United States (Georgia, Iowa, California, and the Pacific Northwest).

Published results from two long-term studies in the Northern Great Plains provide another data set to test the utility of the soil quality index as a way of comparing a diverse array of management 
practices. The first study was a cropping system study initiated in 1984 to compare a 3-year annual cropping system to crop-fallow under three levels of tillage (no-tillage, minimum tillage, and conventional tillage), and three levels of $\mathrm{N}$ fertilization. In 1998, a suite of physical, chemical, and biological soil attributes were compared among these treatments (Wienhold \& Halvorson 1998). In 1999 , differences in potentially mineralizable $\mathrm{N}$ among the treatments were compared (Wienhold \& Halvorson 1999). The second study was a grazing trial initiated in 1916 to assess the effects of grazing pressure on the mixed grass prairie vegetation. In 1932 a fertilized tame grass pasture treatment was added to the grazing trial. In 2001, physical, chemical, and biological soil attributes under no grazing, moderate long-term grazing, heavy long-term grazing, and in the grazed tame pastured were compared (Wienhold et al. 2001). Soils at both the cropping system site and the grazing site were Temvik-Wilton silt loam (finesilty, mixed Typic, and Pachic Haploborolls). Bulk density was selected as a physical attribute; organic $\mathrm{C}$ concentration, electrical conductivity and $\mathrm{pH}$ were selected as chemical attributes; and potentially mineralizable $\mathrm{N}$ was selected as a biological attribute because Andrew's et al. (2002b) had developed scoring curves for these indicators and all five were measured in treatments for both field studies. Values for these five attributes were entered into a spreadsheet, normalized using nonlinear scoring curves, and used to compute a soil quality index by adding the scores. Indices were computed for each of six original treatments (no grazing, moderate grazing, heavy grazing, grazed fertilized tame, conventionally tilled crop-fallow, and no-tillage annually cropped).

In the cropping system study, Wienhold \& Halvorson $(1998,1999)$ concluded that more intensive cropping and conservation tillage increased $\mathrm{N}$-mineralization rates and improved soil quality when compared to crop-fallow. In the grazing trial study, Wienhold et al. (2001) concluded that moderate grazing and grazing fertilized tame pasture were viable management options that appear to sustain the soil resource. Conclusions reached in both of these studies were somewhat subjective in that while they were based on differences in soil attributes, professional judgment was used to describe the implications of those differences on the soil resource. The soil index ranked the treatments:

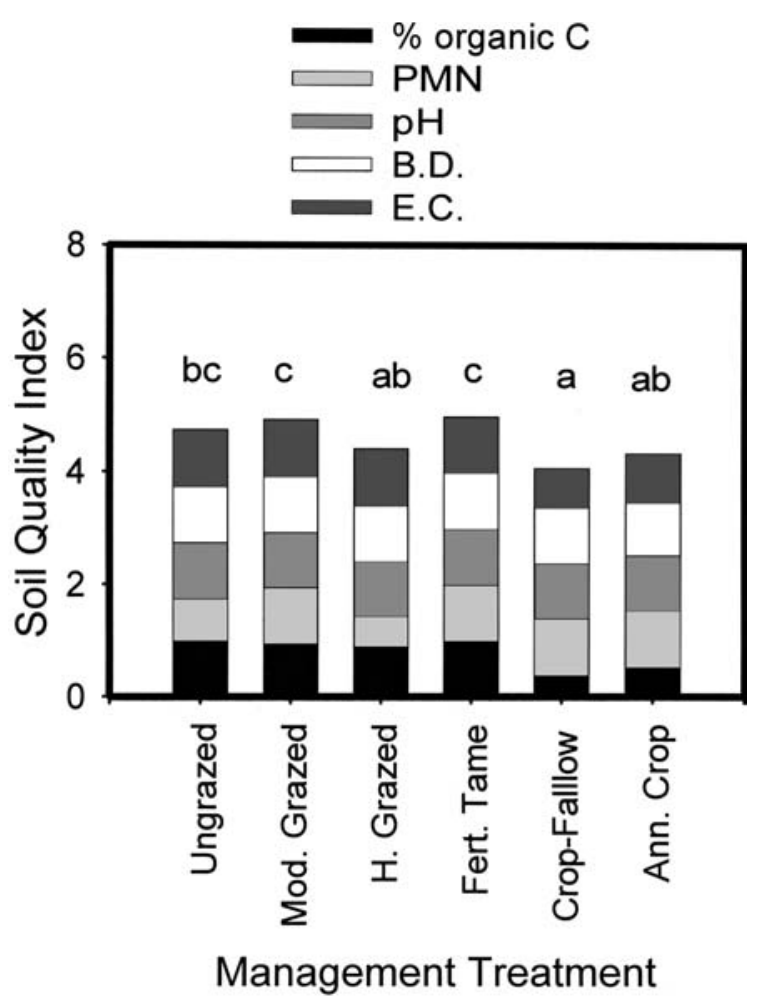

Fig. 3. Soil quality indices for a range of management practices in the Northern Great Plains (mean $\pm 1 \mathrm{SD}$ ). Different letters denote significant differences between management treatments at $p=0.05 . \quad(\mathrm{PMN}=$ potentially mineralizable nitrogen; B.D. = bulk density, E.C. = electrical conductivity.)

grazed fertilized tame pasture $>$ moderately grazed $>$ ungrazed $>$ heavily grazed $>$ annual cropping with no-tillage $>$ conventionally tilled crop-fallow (Figure 3). These results are the same as those in the original reports (Wienhold \& Halvorson 1998, 1999; Wienhold et al. 2001). The soil index is much less subjective in that the same scoring curves were used to normalize the measured soil attributes in both the grazing and cropping systems studies. While work is needed to develop scoring curves for additional soil indicators, the soil quality index appears to have potential for assessing management practices across a wide range of soils.

\section{Conclusions}

Soil quality has emerged as a unifying concept for educating professionals, producers, and the public about the important processes that soils perform 
and as an assessment tool for evaluating current management practices and comparing alternative management practices. Soil attributes comprising a minimum data set have been identified and both laboratory and field methods have been developed for measuring these attributes. Work is currently underway to develop a soil quality assessment index that normalizes soil quality attribute measurements and produces an index value that can be used to compare management practices across a wide range of environments. Initial evaluation of the soil quality index demonstrates that the results generated are reasonable and objective.

\section{References cited}

Andrews SS, Carroll CR. 2001 Designing a decision tool for sustainable agroecosystem management: soil quality assessment of a poultry litter management case study. Ecol Appl 11(6), 1573-1585.

Andrews SS, Mitchell JP, Mancinelli R, Karlen DL, Hartz TK, Horwath WR, Pettygrove GS, Scow KM, Munk DS. 2002a On-farm assessment of soil quality in California's central valley. Agron J 94, 12-22.

Andrews SS, Karlen DL, Mitchell JP 2002b A comparison of soil quality indexing methods for vegetable production systems in northern California. Agric Ecosyt Environ 90, 25-45.

Brejda JJ, Karlen DL, Smith JL, Allan DL. 2000a Identification of regional soil quality factors and indicators: II. Northern Mississippi Loess Hills and Palouse Prairie. Soil Sci Soc Am $J$ 64, 2125-2135.

Brejda JJ, Moorman TB, Karlen DL, Dao TH. 2000b Identification of regional soil quality factors and indicators: I. Central and Southern High Plains. Soil Sci Soc Am J 64, 2115-2124.

Brejda JJ, Moorman TB, Smith JL, Karlen DL, Allan DL, Dao, TH. 2000c Distribution and variability of surface soil properties at a regional scale. Soil Sci Soc Am J 64, 974-982.

Doran JW, Jones AJ. 1996 Methods for Assessing Soil Quality. SSSA Spec. Publ. No. 49. Madison, WI: Soil Sci. Soc. Am., Inc.

Doran JW, Coleman DC, Bezdicek DF, Stewart BA. 1994 Defining Soil Quality for a Sustainable Environment. SSSA Spec. Publ. No. 35. Madison, WI: Soil Sci. Soc. Am., Inc.

Gomez AA, Swete Kelly DE, Syers JK, Coughlan KJ. 1996 Measuring sustainability of agricultural systems at the farm level. In Doran JW, Jones AJ, eds. Methods for Assessing Soil Quality. Spec. Publ. No. 49. Madison, WI: Soil Sci. Soc. Am., pp. 401-409.

Haub C, Farnsworth-Riche M. 1994 Population by the numbers: trends in population growth and structure. In Mazur LA, ed. Beyond the Numbers. Washington, DC: Island Press, pp. 95-108.

Hussain I, Olson KR, Wander MM, Karlen DL. 1999 Adaptation of soil quality indices and application to three tillage systems in southern Illinois. Soil Till Res 50, 237-249.
Jaenicke EC, Lengnick LL. 1999 A soil-quality index and its relationship to efficiency and productivity growth measures: two decompositions. Am J Agric Econ 81, 881-893.

Jenny H. 1941 Factors of Soil Formation, A System of Quantitative Pedology. NY: McGraw Hill.

Karlen DL, Mausbach MJ, Doran JW, Cline RG, Harris RF, Schuman GE. 1997 Soil quality: a concept, definition, and framework for evaluation. Soil Sci Soc Am J 61, 4-10.

Karlen DL, Gardner JC, Rosek MJ. 1998 A soil quality framework for evaluating the impact of CRP. J Prod Agricul 11, 56-60.

Karlen DL, Rosek MJ, Gardner JC, Allan DL, Alms MJ, Bezdicek DF, Flock M, Huggins DR, Miller BS, Staben ML. 1999 Conservation reserve program effects on soil quality indicators. J Soil Water Conserv 54, 439-444.

Larson WE, Pierce FJ. 1991 Conservation and enhancement of soil quality. In Dumanski $\mathrm{J}$ et al., eds. Evaluation for Sustainable Land Management in the Developing World, Vol. 2, Technical Papers, Bangkok, Thailand: Int. Board for Soil Res. and Management, pp. 175-203.

Larson WE, Pierce FJ. 1994 The dynamics of soil quality as a measure of sustainable management. In Doran JW et al., eds, Defining Soil Quality for a Sustainable Environment, Spec. Publ. No. 35. Madison, WI: Soil Sci. Soc. Am., pp. 37-51.

Liebig MA, Doran JW. 1999 Impact of organic production practices on soil quality indicators. J Environ Qual 28, 16011609.

Liebig MA, Doran JW, Gardner JC. 1996 Evaluation of a field test kit for measuring selected soil quality indicators. Agron $J$ 88, 683-686.

National Research Council. 1993 Soil and Water Quality: An Agenda for Agriculture. Washington, DC: National Academic Press.

Pimentel D, Harvey C, Resosudarmo P, Sinclair K, Kurz D, McNair M, Crist S, Shpretz L, Fitton L, Saffouri R, Blair R. 1995 Environmental and economic costs of soil erosion and conservation benefits. Science 267, 1117-1123.

Romig DE, Garlynd JJ, Harris RF. 1996 Farmer-based assessment of soil quality: a soil health scorecard. In Doran JW, Jones AJ, eds. Methods for Assessing Soil Quality. Spec Publ No 49. Madison, WI: Soil Sci Soc Am, pp. 39-60.

Rosegrant MW, Leach N, Gerpacio RV. 1998 Alternative Futures for World Cereal and Meat Consumption. Washington, DC: International Food Policy Institute.

Seybold CA, Mausbach MJ, Karlen DL, Rogers HH. 1998 Quantification of soil quality. In Lal R, Kimble JM, Follett RF, Stewart BA, eds. Soil Processes and the Carbon Cycle. Boca Raton, FL: CRC Press LLC, pp. 387-404.

USDA-NRCS. 1998 Soil Quality Test Kit Guide. Section 1. Test Procedures, and Section 2. Background and Interpretive Guide for Individual Tests, USDA-NRCS. Ames, IA: Soil Quality Institute.

Wander MM, Bollero GA. 1999 Soil quality assessment of tillage impacts in Illinois. Soil Sci Soc Am J 63, 961-971.

Warkentin BP, Fletcher HF. 1977 Soil quality for intensive agriculture. In Proc Int Sem on Soil Environ and Fert Manage in Intensive Agric Soc Sci Soil and Manure. Tokyo: Natl Inst of Agric Sci, pp. 594-598.

Wienhold BJ, Halvorson AD. 1998 Cropping system influences on several soil quality attributes in the northern Great Plains. J Soil Water Conserv 53, 254-258. 
Wienhold BJ, Halvorson AD. 1999 Nitrogen mineralization responses to cropping, tillage, and nitrogen rate in the Northern Great Plains. Soil Sci Soc Am J 63, 192-196.
Wienhold BJ, Hendrickson JR, Karn JF. 2001 Pasture management influences on soil properties in the Northern Great Plains. J Soil Water Conserv 56, 27-31. 